\title{
APRIL, a new member of the tumor necrosis factor family, modulates death ligand-induced apoptosis
}

\author{
W Roth ${ }^{1,4}$, B Wagenknecht ${ }^{1}$, A Klumpp ${ }^{1}$, U Naumann ${ }^{1}$, \\ M Hahne ${ }^{2,3}$, J Tschopp ${ }^{3}$ and M Weller ${ }^{*, 1}$ \\ ${ }^{1}$ Laboratory of Molecular Neuro-Oncology, Department of Neurology, \\ University of Tübingen, Tübingen, Germany \\ 2 Department of Immunology \& Oncology, Universidad Autónoma, Madrid, \\ Spain \\ 3 Institute of Biochemistry, University of Lausanne, Epalinges, Switzerland \\ ${ }^{4}$ Current address: The Burnham Institute, La Jolla, California 92037, USA \\ * Corresponding author: M Weller, Laboratory of Molecular Neuro-Oncology, \\ Department of Neurology, University of Tübingen, Medical School, Hoppe- \\ Seyler-Strasse 3, 72076 Tübingen, Germany. Tel: +49 7071 2982141; \\ Fax: +49 7071 295260; E-mail: michael.weller@uni-tuebingen.de
}

Received 21.7.00; revised 20.11.00; accepted 7.12.00

Edited by S Nagata

\begin{abstract}
APRIL (a proliferation-inducing ligand) is a newly identified member of the tumor necrosis factor (TNF) family. Tumor growth-promoting as well as apoptosis-inducing effects of APRIL have been described. Here, we report that five of 12 human malignant glioma cell lines express APRIL. APRIL gene transfer experiments revealed that malignant glioma cells are refractory to growth-promoting activity of APRIL in vitroand in vivo. Interestingly, ectopic expression of APRIL confers minor protection from apoptotic cell death induced by the death ligands, CD95 ligand (CD95L) and tumor necrosis factorrelated apoptosis-inducing ligand (TRAIL)/Apo2 ligand (Apo2L). This antiapoptotic activity is specific for death ligand/receptor-mediated apoptosis since APRIL does not protect glioma cells from the cytotoxicity of the drugs, teniposide, vincristine, lomustine or cisplatin. Ectopic expression of APRIL is associated with the upregulation of X-linked inhibitor of apoptosis protein (XIAP), providing a possible explanation for the antiapoptotic activity observed here. In contrast, APRIL does not regulate the expression levels of the antiapoptotic proteins FLICE-inhibitory protein (FLIP), Bcl-2 or Bcl- $X_{L}$. These findings suggest that APRIL is involved in the regulation of death ligand-induced apoptotic signaling in malignant glioma cells. Cell Death and Differentiation (2001) 8, 403-410.
\end{abstract}

Keywords: APRIL (a proliferation-inducing ligand); apoptosis; glioma; death ligands; CD95L; TRAIL/Apo2L

Abbreviations: TNF, tumor necrosis factor; APRIL, a proliferationinducing ligand; XIAP, X-linked inhibitor of apoptosis protein

\section{Introduction}

Cytokines of the tumor necrosis factor (TNF) family exhibit a broad range of different functions. ${ }^{1}$ TNF- $\alpha$ is a pleiotropic cytokine with proinflammatory properties whereas CD95L and TRAIL/Apo2L induce apoptotic death of cells expressing the cognate receptors. ${ }^{2-4}$ Other members of the TNF family, such as TRANCE, LIGHT and TWEAK, are involved in the regulation of immunologic processes and tissue homeostasis. $^{5-9}$ APRIL (a proliferation inducing ligand, TRDL-1, TNFrelated death ligand-1) is a newly identified type II membrane protein that belongs to the TNF family. APRIL is predominantly expressed in malignant tumors and promotes growth in several malignant tumor cell lines in vitro and in vivo. ${ }^{10}$ However, other authors found that APRIL/TRDL-1 has proapoptotic activity, similar to CD95L, presumably by binding to CD95. ${ }^{11}$ Thus, APRIL seems to be involved in the regulation of death and proliferation of tumor cells, but there are still contradictory findings regarding its overall biological effects. Here, we investigated the effects of APRIL expression on proliferation and sensitivity to apoptosis of human malignant glioma cells.

\section{Results}

\section{Expression of APRIL by human malignant glioma} cell lines

First, we examined whether human malignant glioma cells express APRIL in vitro. RT - PCR revealed the expression of APRIL mRNA in five of 12 cell lines (Figure 1A). This panel of cell lines has been characterized before. ${ }^{12,13}$ A comparison of APRIL mRNA expression and the expression of other members of the TNF family (CD95L, TRAIL/Apo2L), of the TNF receptor family (CD95, death receptors (DR) 4 and 5), or of the antiapoptotic proteins Bcl-2, Bcl-X $\mathrm{X}_{\mathrm{L}}$, FLIP or XIAP, did not reveal significant correlations as determined by Spearman rank order correlation analysis (data not shown). Similarly, there was no correlation of APRIL expression with the susceptibility of the glioma cells to CD95L or TRAIL/Apo2L, or to the cytotoxic drugs vincristine, lomustine, cytarabine, teniposide, doxorubicin, camptothecin, paclitaxel or gemcitabine, analyzed by ANOVA (data not shown).

APRIL does not promote glioma cell growth in vitro or in vivo

To investigate the effects of APRIL on the regulation of proliferation and cell cycle control, we stably transfected three glioma cell lines (LN-18, LN-229, U373MG) with the pCR3 plasmid that contains FLAG-tagged full length APRIL cDNA and a neomycin resistance gene. The stable expression of transgenes was verified by Northern blot analysis (Figure 1B) 
A
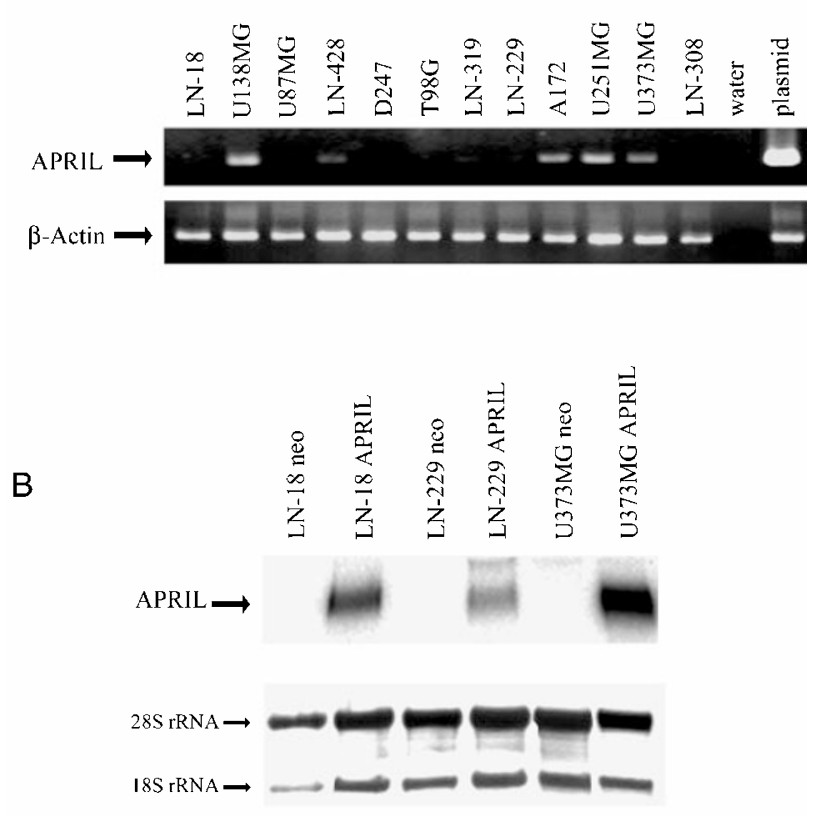

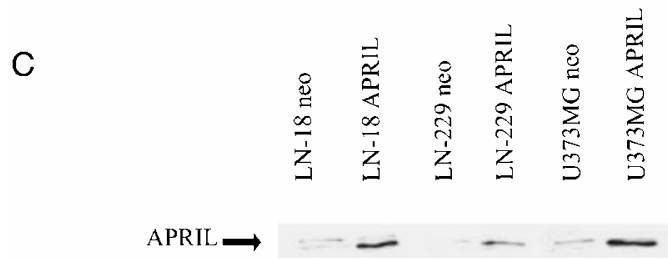

Figure 1 APRIL expression and APRIL gene transfer in human malignant glioma cells. (A) RT-PCR analysis of APRIL expression in human long-term malignant glioma cell lines (upper panel). The pCR3-APRIL plasmid is used as a positive control. The lower panel shows $\beta$-actin as an internal control for equal amplification. (B) Verification of transgene expression in APRILtransfected glioma cell lines by Northern blot analysis. The Northern blot demonstrates the enhanced expression of APRIL cDNA in LN-18, LN-229 and U373MG cells. Each lane contains $10 \mu \mathrm{g}$ RNA (lower panel: $28 \mathrm{~S}$ and $18 \mathrm{~S}$ rRNA control). (C) Verification of transgene expression in APRIL-transfected glioma cell lines by immunoblot analysis. Protein lysates were prepared from LN-18, LN-229 and U373MG cells transfected with expression plasmids for FLAG-tagged APRIL CDNA or the respective control plasmids. The blotting membrane was probed with an anti-FLAG antibody. FLAG-tagged APRIL protein migrates at approximately $40 \mathrm{kDa}$

and immunoblot analysis of FLAG-tagged APRIL (Figure 1C). After selection, pooled transfectants were subjected to cell cycle analysis by flow cytometry. There was no difference in the cell cycle distribution between APRIL transfectants and neo control cells when the cells were allowed to proliferate in complete DMEM medium. Further, there was also no difference in cell cycle distribution after serum deprivation (data not shown). Next, we determined the generation times (doubling times) of the different cell lines. No differences in the generation times of APRIL transfectants and neo control cells were observed (LN-18 APRIL, $1.2 \pm 0.1$ days; $\mathrm{LN}-18$ neo, $1.3 \pm 0.2$ days; $L N-229$ APRIL, $1.5 \pm 0.2$ days; $L N-229$ neo, $1.5 \pm 0.1$ days; U373MG APRIL, $1.7 \pm 0.2$ days; U373MG neo, $1.6 \pm 0.1$ days). We also examined the resistance of the different cell lines to serum withdrawal. Cells were switched to serum-free medium and the density of viable cells was measured after 3 and 7 days. Glioma cells ectopically expressing APRIL did not exhibit altered growth kinetics compared with neo control cells under conditions of serum deprivation (data not shown). In view of the APRIL-mediated growth promotion of $\mathrm{NIH}-3 \mathrm{~T} 3$ xenografts in nude mice, ${ }^{10}$ we also investigated the effects of ectopic APRIL expression on the growth of intracerebrally growing U373MG gliomas. APRIL transgene-expressing U373MG cells and, as a control, U373 neo cells were implanted intracerebrally into athymic mice. The animals were sacrificed 30 days after inoculation of glioma cells. U373MG xenografts were densely cellular and sometimes surrounded by small nodules of tumor cells (Figure 2A, B). Necrosis or blood vessels were not seen in xenografts of either cell line. There were no morphological differences between xenografts formed by U373MG neo and APRIL cells. APRIL expression of stably transfected, intracerebrally growing glioma was confirmed by immunohistochemistry as demonstrated in Figure 2D. APRIL was found mainly in the cytoplasm of glioma cells. Sections derived from neo control tumors showed no specific labeling (Figure 2C). Figure 2E shows that APRIL expressing glioma xenografts $(n=8)$ were not significantly larger than xenografts formed by control cells.

\section{APRIL inhibits death ligand-induced apoptosis}

Since several members of the TNF family are involved in the regulation of apoptotic cell death, we examined possible apoptosis-modulating effects of APRIL. APRIL transfectants and control cells were treated with the proapoptotic death ligands CD95L and TRAIL/Apo2L for $24 \mathrm{~h}$. LN-18 cells are highly susceptible to these death ligands whereas LN-229 and U373MG cells become susceptible to CD95L- and TRAIL/Apo2L-induced cell death when cotreated with the protein synthesis inhibitor cycloheximide. ${ }^{12,14}$ APRIL-producing transfectants of the cell lines LN-229 and U373MG were significantly more resistant to both death ligands than neo control cells (Figure 3A, B). Time course experiments demonstrated that the antiapoptotic effects mediated by APRIL were most prominent after a $20-36 \mathrm{~h}$ treatment with CD95L. Treatment of glioma cells with cycloheximide alone $(10 \mu \mathrm{g} / \mathrm{ml})$ was not toxic. Interestingly, APRIL failed to protect the highly susceptible $\mathrm{LN}-18$ cells from CD95Land TRAIL/Apo2L-induced cell death (Figure 3C). In contrast to the death ligands, cytotoxic drug-mediated cell death was unaffected by ectopic expression of APRIL. Vincristine, teniposide, lomustine and cisplatin killed glioma cells irrespective of the presence of APRIL (Figure 3D-F). Since we have previously described caspase 3 as a key executioner in death ligand-induced apoptosis of malignant glioma cells, ${ }^{15}$ we next examined the induction of caspase 3-like activity by CD95L in APRIL- versus control-transfected glioma cells. APRIL transgene expression resulted in significant inhibition of DEVD-amc cleavage upon treatment with CD95L, both in the absence and presence of $\mathrm{CHX}$, in $\mathrm{LN}-229$ and U373MG cells (Figure 4). 

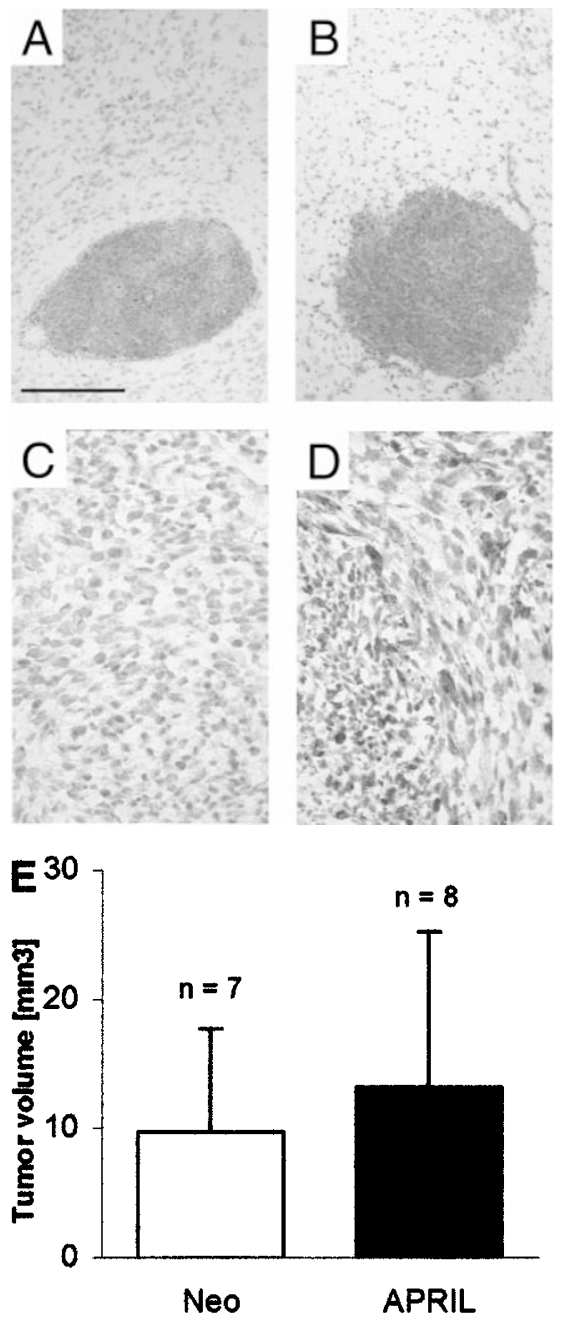

Figure 2 No modulation of glioma cell growth by ectopic APRIL expression in vivo. (A,B) Intracerebrally inoculated U373MG neo control (A) and APRIL (B) glioma cells form densely cellular xenografts in nude mice (magnification: bar $=500 \mu \mathrm{m})$. (C,D) Ectopic expression of APRIL in human U373MG glioma xenografts was examined by immunohistochemistry. Glioma xenografts overexpressing APRIL (D) stained positive for the transgene product, whereas, in U373MG neo tumors, APRIL was not detected (C) (bar $=75 \mu \mathrm{m})$. (E) The growth of intracranial U373MG glioma xenografts in nude mice is independent of APRIL expression. The mice were sacrificed at day 30 after tumor cell inoculation. Xenograft volumes were determined using MCID software (APRIL, $n=8$; neo, $n=7, \pm$ S.D., $t$-test: $P>0.05$ )

\section{APRIL-mediated protection from death ligand-dependent apoptosis is associated with up-regulation of XIAP levels}

The TNF family comprises several signaling proteins that are cleaved from the cell surface and, thereafter, function as soluble cytokines. Since APRIL is a member of the TNF family, we speculated whether it could also be secreted in the extracellular space and might exert its antiapopotic effects by triggering a cytoprotective signaling cascade upon binding to distinct cell surface receptors. Thus, we transferred cell culture supernatant from U373MG APRIL glioma cells to U373MG neo cells and treated them with death ligands in the presence of cycloheximide. However, neo control cells were not protected from CD95L- and TRAIL/Apo2L-induced apoptotic cell death. Similar results were obtained with LN229 glioma cells (data not shown). To further elucidate the antiapoptotic mechanisms of APRIL, we investigated the expression levels of diverse proteins that are known to counteract death receptor-mediated apoptotic cell death. We found that the expression of the protooncogene products Bcl2 and $\mathrm{Bcl}-\mathrm{X}_{\mathrm{L}}$ was not significantly modified in APRILtransfected glioma cells and that FLIP expression was not enhanced in APRIL transfectants compared with neo control cells (Figure 5A). In contrast, APRIL-overexpressing LN-229 and U373MG glioma cells exhibited moderately, but consistently elevated levels of XIAP (Figure 5B). In contrast, glioma cells of the cell line LN-18 did not respond to APRIL transfection with enhanced XIAP expression, consistent with enhanced resistance of APRIL transfectants of LN-229 and U373MG but not LN-18 cells (Figure 3A-C).

\section{Discussion}

The survival of patients with malignant gliomas rarely exceeds 2 years because these tumors are resistant to the current treatment strategies. The failure of radiotherapy and adjuvant chemotherapy to achieve long-term remissions has been attributed to the molecular resistance of glioma cells to a broad range of cell death stimuli (reviewed i ${ }^{16}$ ). Antiapoptotic proteins such as Bcl-2, ${ }^{17}$ XIAP $^{18}$ and FLIP ${ }^{19}$ may be involved in the resistance to apoptotic cell death induced by anticancer drugs or immune effector cells. The latter may have the ability to kill tumor cells not only by perforin but also by proapoptotic death ligands. ${ }^{20-22}$ Resistance to the death ligands CD95L and TRAIL/Apo2L may ensue from the expression of decoy receptors that bind to and neutralize the respective death ligands. $^{23}$

APRIL, a recently identified member of the TNF family, was reported to promote the growth of tumor cells in vitro and in vivo. ${ }^{10}$ However, interactions of APRIL/TRDL-1 and CD95 may also induce apoptotic death of Jurkat cells. ${ }^{11}$ Given these contradictory findings, we sought to shed light on the possible role of APRIL in regulating growth and sensitivity to apoptosis of malignant glioma cells. Thus, we demonstrate that a subset of long-term glioma cell lines express APRIL mRNA (Figure 1A). After having established stable transfectants engineered to express high levels of APRIL (Figure 1B, C), we investigated proliferation and cell cycle regulation under normal growth conditions in complete medium and after serum withdrawal, thereby modeling poor growth conditions in vitro. We find that APRIL does not modulate cell growth in vitro. Additionally, possible growth-promoting actions of APRIL were evaluated by in vivo experiments. Intracerebrally implanted glioma xenografts with enhanced APRIL expression did not grow faster than the control tumors in nude mice (Figure 2E). As previously shown, most of the lymphoma cell lines examined were responsive to APRIL-induced growth promotion whereas the breast carcinoma cell line MCF-7 was not. ${ }^{10}$ Thus, APRIL-mediated growth stimulation appears to be cell type-specific, and cell lines derived from hematological malignancies may respond better to APRIL than cell lines from solid tumors, such as gliomas. 


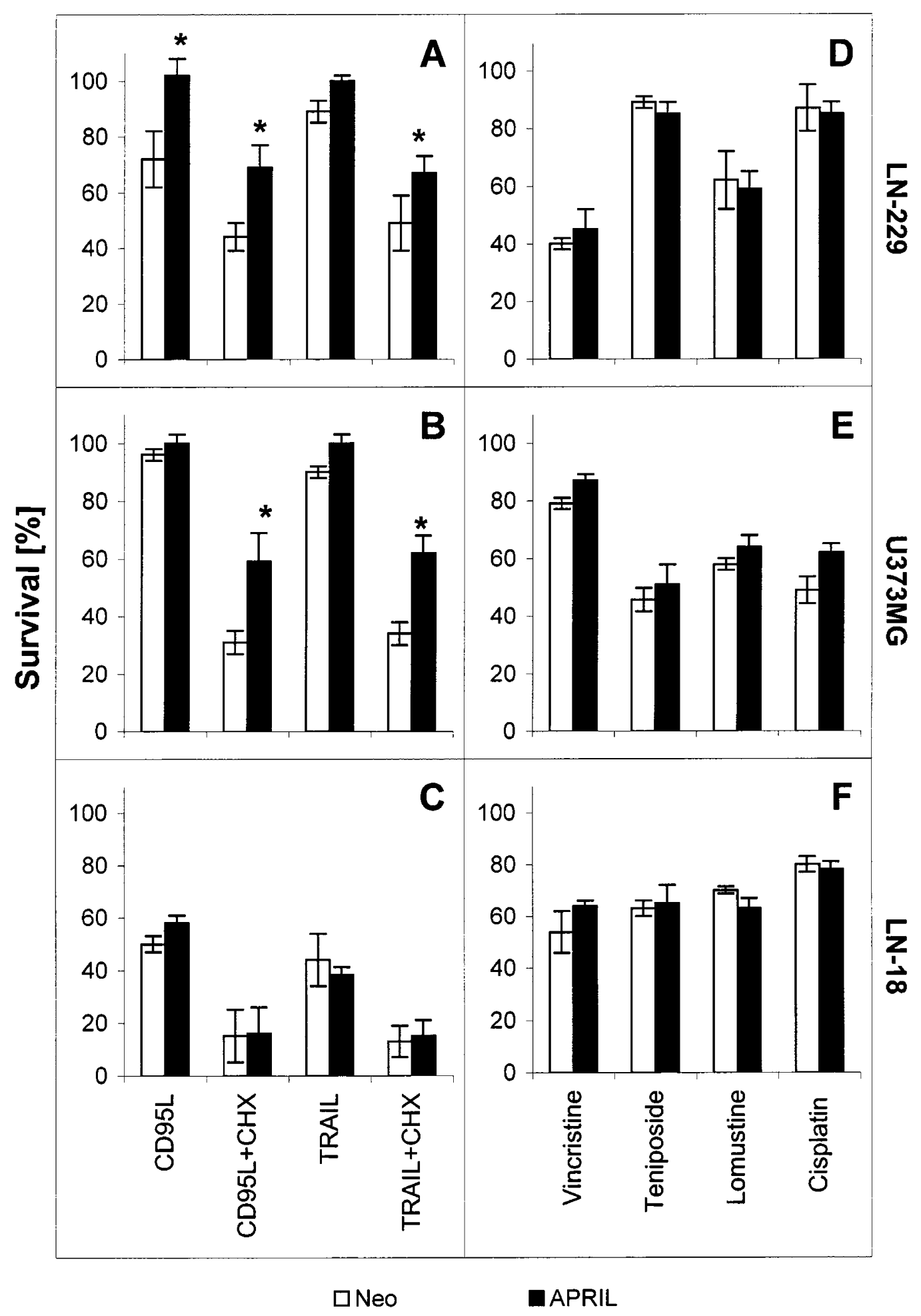

Figure 3 APRIL modulates death receptor-mediated apoptosis. The glioma cells were exposed to CD95L (10 U/ml) or TRAIL/Apo2L (50 ng/ml) in the absence or presence of cycloheximide $(10 \mu \mathrm{g} / \mathrm{ml})(\mathbf{A}-\mathbf{C})$, or to vincristine $(\mathrm{LN}-229,10 \mu \mathrm{M}$; U373MG, LN-18, $1 \mu \mathrm{M})$, teniposide $(100 \mu \mathrm{M})$, lomustine $(500 \mu \mathrm{M})$ or cisplatin $(100 \mu \mathrm{M})$ for $24 \mathrm{~h}(\mathbf{D}-\mathbf{F})$. Data are expressed as means of the relative percentage of cell survival $(n=3, \pm$ S.D.). The asterisk indicates survival values of APRILtransfected cells that were significantly different from the survival values of neo control cells $(P<0.05, t$-test $)$

The reasons for these diverging responses are unknown. We hypothesize that glioma cells may lack target genes or essential signaling molecules required for mitogenic signal transduction induced by APRIL. Recently, two receptors for 


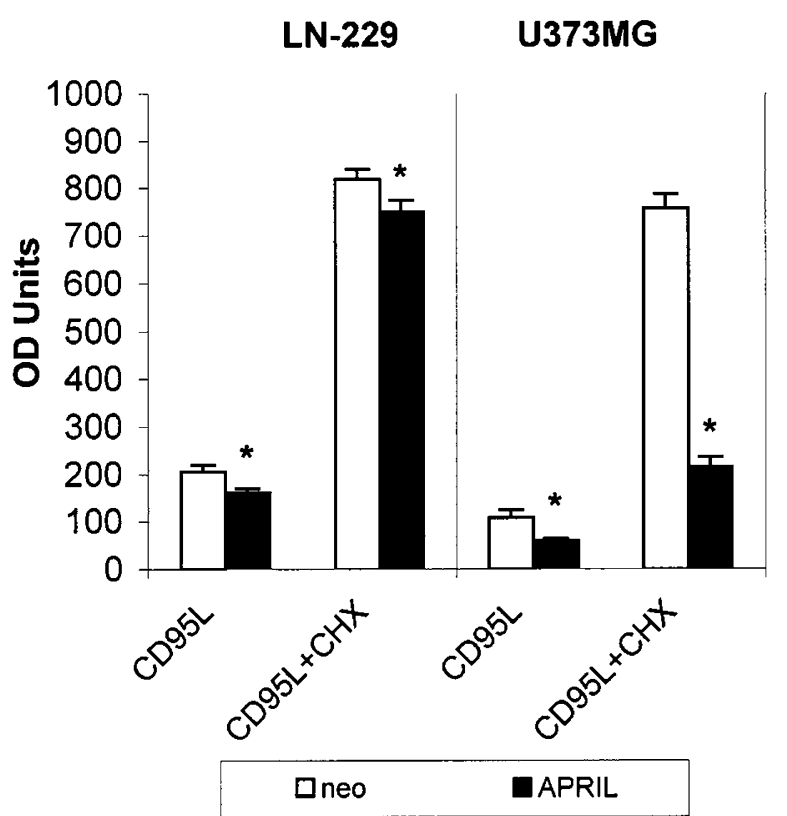

Figure 4 CD95L-induced activation of caspase 3-like protease activity is decreased in APRIL transgene-expressing cells. APRIL-transfected or neo control cells of the glioma cell lines LN-229 (left) or U373MG (right) were treated with CD95L $(30 \mathrm{U} / \mathrm{ml})$ in the absence or presence of $\mathrm{CHX}(10 \mu \mathrm{g} / \mathrm{ml})$. Caspase 3-like protease activity was determined using a fluorescent substrate assay and is expressed in optical density (OD) units (mean \pm S.D., $n=3$, ${ }^{*} P<0.05, t$-test, APRIL compared with neo)

APRIL, BCMA (B $\underline{\mathrm{B}}$ cell maturation antigen) and $\mathrm{TACl}$ (transmembrane activator and CAML interactor), were identified. ${ }^{24,25}$ Marsters et al. ${ }^{24}$ demonstrated that APRIL binds specifically to $\mathrm{TACl}$ and BCMA and thereby activates nuclear factor- $\kappa \mathrm{B}(\mathrm{NF}-\kappa \mathrm{B})$. Similarly, Wu et al. ${ }^{25}$ characterized $\mathrm{TACl}$ as a receptor for APRIL and reported that $\mathrm{TACl}$ mRNA was found predominantly in $B$ cells. In peripheral blood B cells, the interaction of APRIL with its receptors results in enhanced immunglobulin $M$ production. ${ }^{24}$ Future investigations will show whether $\mathrm{TACl}$ and $\mathrm{BCMA}$ are expressed in malignant glioma cells and whether their absence may be responsible for the refractoriness of glioma cells to APRIL-induced growth promotion. Moreover, it will be interesting to examine whether TACI, BCMA or some other receptor(s) mediate the antiapoptotic effects of APRIL that have been observed in this study (Figures 3 and 4).

The partial protection of glioma cells from death ligandinduced apoptosis by overexpression of APRIL requires a cross-talk between CD95L- or TRAIL/Apo2L-induced apoptotic signaling and the APRIL signaling pathway. Interestingly, APRIL did not protect cells from anticancer drug-induced cell death although these drugs have been shown to trigger apoptosis in glioma cells ${ }^{14,26,27}$ (and unpublished observations). Given the specificity of the APRIL-mediated antiapoptotic effect for death ligandinduced apoptosis, we hypothesized that APRIL may interfere with distinct proteins of the proximal signalling cascade triggered by death ligands. Important antiapoptotic proteins that have been demonstrated to protect malignant
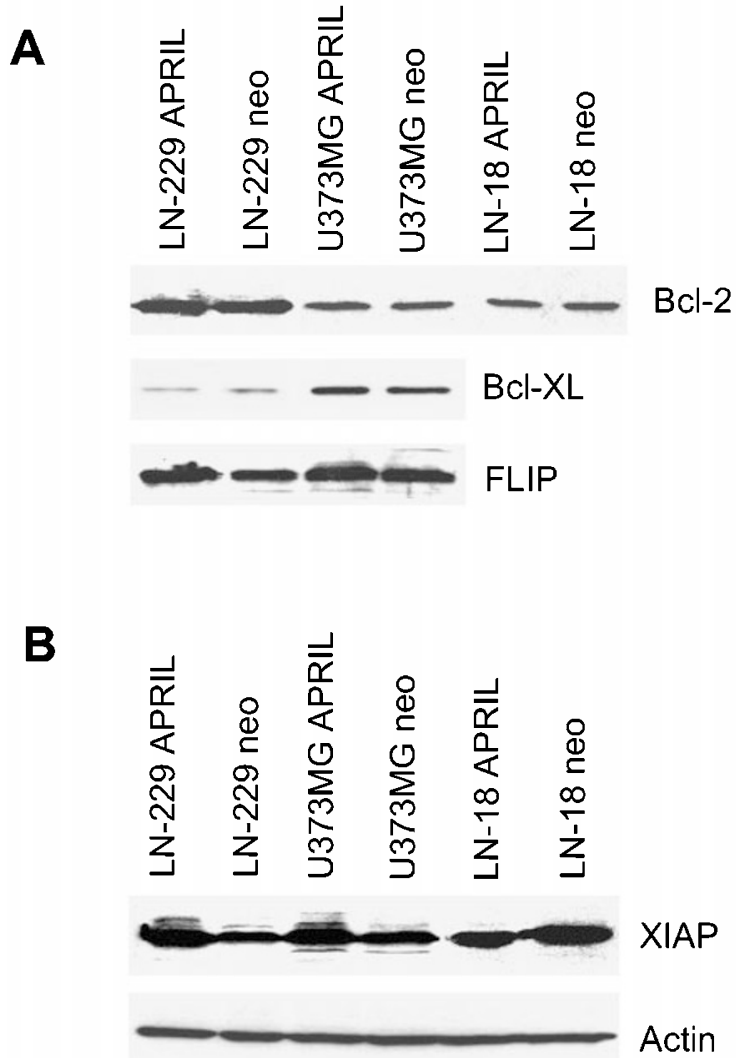

Figure 5 Modulation of antiapoptotic protein expression by APRIL. (A) Bcl-2, $\mathrm{Bcl}-\mathrm{X}_{\mathrm{L}}$ and FLIP levels were examined in whole cell lysates of human glioma cells. No differences of $\mathrm{BCl}-2, \mathrm{BCl}-\mathrm{X}_{\mathrm{L}}$ or FLIP expression levels mediated by APRIL transgene expression were observed. (B) XIAP levels assessed by immunoblot analysis were moderately enhanced in APRIL-transfected LN-229 and U373MG, but not LN-18, glioma cells (lower panel: actin loading control)

glioma cells from CD95L- and TRAIL/Apo2L-induced apoptosis are $\mathrm{Bcl}-2,{ }^{26} \mathrm{Bcl}-\mathrm{X}_{\mathrm{L}}$ (Glaser et al., submitted), FLIP (Röhn et al., submitted) and XIAP. ${ }^{28}$ While the expression of $\mathrm{Bcl}-2, \mathrm{Bcl}-\mathrm{X}_{\mathrm{L}}$ and FLIP was unaltered after APRIL gene transfer, there was a weak, but consistent increase in XIAP levels in those glioma cell lines overexpressing APRIL that were protected from apoptosis, LN-229 and U373MG (Figure 5). XIAP is a member of the family of inhibitor-of-apoptosis proteins (IAP) that are thought to block cell death via direct inhibition of caspases 3,7 and $9 .^{29,30}$ In glioma cells, adenoviral XIAP gene transfer results in inhibition of caspase 8 and 3 processing after CD95 triggering. ${ }^{28}$ Corresponding to these data, glioma cells overexpressing APRIL exhibited decreased caspase 3-like activity in response to treatment with CD95L (Figure 4). Induction of XIAP under conditions of resistance to apoptosis has been described before. For example, IAP genes were found to be strongly up-regulated upon treatment of endothelial cells with $\mathrm{TNF}-\alpha$, resulting in protection from TNF- $\alpha$-induced apoptosis. There, XIAP expression was regulated by $\mathrm{NF}-\kappa \mathrm{B} .^{31}$ In that regard, the recent observations ${ }^{24,25}$ of enhanced $\mathrm{NF}-\kappa \mathrm{B}$ activity mediated by APRIL when binding to its receptors TACl or 
BCMA supports the idea that APRIL-mediated NF- $\kappa \mathrm{B}$ activation leads to enhanced levels of XIAP in glioma cells. Of note, protection from death ligand-induced apoptosis in LN-18 glioma cells was insignificant (Figure $3 \mathrm{C})$, and XIAP expression in $\mathrm{LN}-18$ cells ectopically producing APRIL was not enhanced (Figure 5B). These findings support a role for increased XIAP levels in the regulation of APRIL-induced effects on cell survival. Further, of the antiapoptotic proteins examined, Bcl-2 and $\mathrm{Bcl}-\mathrm{X}_{\mathrm{L}}$ inhibit drug-induced cell death whereas XIAP does not (unpublished observations). This is probably a consequence of the preferential action of XIAP on caspase 3 and the negligible role of caspase 3 for drug-induced apoptosis in glioma cells. ${ }^{32}$ Consequently, the idea of XIAP mediating protective effects of APRIL fits nicely with the failure of APRIL to modulate drug-induced apoptosis (Figure 3D-F). However, it must be emphasized that the overall antiapoptotic activity of APRIL characterized here is moderate. Therefore, its biological significance can not be finally assessed. Further studies are needed to corroborate a APRIL-mediated antiapoptotic activity in diverse cell lines in vitro and in vivo. In contrast to our results, Kelly et al. ${ }^{11}$ reported proapoptotic effects of APRIL, suggested to involve ligand-receptor interactions of APRIL and CD95. Since the highly CD95L-susceptible cell line, LN-18, was unaffected by overexpression of APRIL, CD95-dependent proapoptotic effects of APRIL may not be relevant to malignant glioma cells.

\section{Materials and Methods}

\section{Materials and cell culture}

Vincristine, cycloheximide and cisplatin were from Sigma (Deisenhofen, Germany). Lomustine was obtained from Medac (Hamburg, Germany). Teniposide was provided by Sandoz Pharma AG (Basel, Switzerland). All human glioblastoma cell lines were kindly provided by Dr. N de Tribolet (Lausanne, Switzerland). Soluble CD95L was obtained from murine CD95L-transfected N2A neuroblastoma cells. ${ }^{14}$ Purified human Apo2L (TRAIL) was kindly provided by Dr. A Ashkenazi (Genentech, CA, USA). The glioma cells were maintained as described. ${ }^{14}$ Doubling times were determined during logarithmic growth in 24-well plates. The cells $\left(10^{3}\right)$ were seeded, and viable cell counts were obtained daily for 7 days by trypan blue exclusion. Acute cytotoxic cell death assays were performed as described. ${ }^{14}$ Glioma cells stably expressing human APRIL were obtained by lipofection with SuperFect (Qiagen, Hilden, Germany) using the FLAG-tagged, fulllength APRIL-containing PCR3 expression vector that harbors a neomycin (neo) resistance gene. ${ }^{10}$ As a control, cells were transfected with the pcDNA3 neo control plasmid. The cells were selected with neomycin $(500 \mu \mathrm{g} / \mathrm{ml})$, starting $48 \mathrm{~h}$ after transfection. All experiments were carried out with pooled transfectants to avoid cloning or selection artifacts.

\section{RT - PCR}

RNA was prepared by the RNeasy Mini kit (Quiagen, Hilden, Germany) according to a standard protocol. RT - PCR was performed according to standard procedures as outlined previously. ${ }^{12}$ Primer sequences and amplification conditions were as follows: APRIL: 35 cycles, denaturation $95^{\circ} \mathrm{C} / 45 \mathrm{~s}$, annealing $68^{\circ} \mathrm{C} / 45 \mathrm{~s}$, extension $72^{\circ} \mathrm{C} / 60 \mathrm{~s}$, primer sequences GCTCATGCCAGCCTCATCTC (nucleotides 278297) and CCAGGTGCAGGACAGAGTGCT (nucleotides 622-642); $\beta$ actin: 35 cycles, denaturation $95^{\circ} \mathrm{C} / 45 \mathrm{~s}$, annealing $53^{\circ} \mathrm{C} / 45 \mathrm{~s}$, extension $72^{\circ} \mathrm{C} / 60 \mathrm{~s}$, primer sequences TGTTTGAGACCTTCAACACCC (nucleotides 409-429) and AGCACTGTGTTGGCGTACAG (nucleotides 918-937). The PCR fragments were separated in $2 \%$ agarose gels and visualized by ethidium bromide.

\section{Northern blot analysis}

Total RNA was extracted using the RNA purification system (RNeasy, Quiagen, Hilden, Germany) according to the manufacturer's instructions. For Northern analysis, $10 \mu \mathrm{g}$ of total RNA were denatured and separated by electrophoresis on $1.2 \%$ agarose gels. After electrophoresis RNA was transferred to nylon membranes (Hybond N, Amersham, Braunschweig, Germany). The filters were hybridized with ${ }^{32} \mathrm{P}$-labeled APRIL cDNA probes. After hybridization, the filters were washed with $1 \times 1 \%$ SSC $/ 1 \%$ SDS and $1 \times 0.1 \%$ SSC/ $1 \%$ SDS for $30 \mathrm{~min}$ at $65^{\circ} \mathrm{C}$. Bound radioactivity was quantified on a phospho-imager using the TINA program (Fushi BasReader 1500, Raytest, Staubenhardt, Germany). APRIL mRNA and $28 \mathrm{~S}$ and $18 \mathrm{~S}$ rRNA were detected by methylene blue staining.

\section{Immunoblot analysis}

Immunoblots were performed as outlined previously. ${ }^{33}$ Twenty $\mu \mathrm{g}$ protein per lane was separated on polyacrylamide gels $\left(\mathrm{Bcl}-2, \mathrm{Bcl}-\mathrm{X}_{\mathrm{L}}\right.$ : 15\%; FLIP, XIAP, FLAG-APRIL: 10\%) and blotted onto nitrocellulose by standard procedures. The membranes were washed, incubated with primary antibody (FLIP NF6: $1: 10,{ }^{34}$; XIAP: $1: 1000,{ }^{18}$; Bcl$2: 2 \mu \mathrm{g} / \mathrm{ml}$, Santa Cruz, Santa Cruz, CA, USA; Bcl-X $: 2 \mu \mathrm{g} / \mathrm{ml}$, Santa Cruz, Santa Cruz, CA, USA; FLAG M2: $2 \mu \mathrm{g} / \mathrm{ml}$, Sigma, Deisenhofen, Germany), washed and incubated with secondary antibody (protein A or anti-mouse IgG, Amersham, Braunschweig, Germany). Enhanced chemiluminescence reagents (Amersham) were used for detection.

\section{Determination of caspase-3-like activity}

Caspase 3 -like activity was measured by DEVD-amc cleavage. Briefly, $10^{4}$ glioma cells were plated in 96-well plates, adhered for $24 \mathrm{~h}$, and incubated with CD95L or CD95L plus cycloheximide (CHX) for $6 \mathrm{~h}$. The cells were lysed in lysis buffer $(60 \mathrm{mM} \mathrm{NaCl}, 5 \mathrm{mM} \mathrm{TRIS} / \mathrm{HCl}$, $2.5 \mathrm{mM}$ EDTA, $0.25 \%$ NP40) for $10 \mathrm{~min}$. Subsequently, the fluorogenic caspase-3 substrate DEVD-amc $(20 \mu \mathrm{M})$ was added to the lysates. Fluorescence was measured using a CytoFluor 2300 cytofluorometer.

\section{Flow cytometry}

Cell cycle analysis by flow cytometry was performed as described previously. ${ }^{35}$ Briefly, the glioma cells were cultured in DMEM, washed, incubated with trypsin for $1 \mathrm{~min}$ at $37^{\circ} \mathrm{C}$, harvested, washed and fixed with $70 \%$ ice-cold ethanol. The cells $\left(10^{6}\right.$ per condition) were stained with propidium iodide (50 $\mu \mathrm{g} / \mathrm{ml}$ in PBS, containing $100 \mu \mathrm{g} / \mathrm{ml}$ RNase A), washed and subjected to flow cytometric analysis of DNA content using a Becton Dickinson FACScalibur cytometer.

\section{Animal studies}

All animal work was carried out in accordance with the NIH guidelines 'Guide for the Care and Use of Laboratory Animals'. Athymic mice (CD1 ${ }^{\mathrm{TM}}$ nu/nu, Charles River, Sulzfeld, Germany) were anesthetized with $7 \%$ chloral hydrate. For intracranial implantation, the mice were placed in a stereotactic fixation device (Stoelting, Wood Dale, IL, 
USA). A burr hole was drilled in the skull $2 \mathrm{~mm}$ lateral to the bregma. The needle of a Hamilton syringe (Hamilton, Darmstadt, Germany) was introduced to a depth of $3 \mathrm{~mm}$. Five $\times 10^{4}$ U373MG glioma cells in $4 \mu \mathrm{l}$ PBS were injected into the right striatum. The mice were observed daily and sacrificed by an overdose of anesthetic 30 days after the inoculation of tumor cells. Cryostat sections of the brains were produced and stained as described before. ${ }^{36}$ For the assessment of tumor volume, cryostat sections were obtained at regular intervals, routinely stained with $\mathrm{H} \& \mathrm{E}$ and subjected to an analysis of tumor volumes using MCID software (Imaging Research Inc., Ontario, Canada).

\section{Immunohistochemistry}

Immunohistochemistry was performed as outlined previously. ${ }^{35}$ Rabbit polyclonal antibody to APRIL was diluted in TRIS-buffered saline (TBS) and applied as primary antibody to the sections overnight at a concentration of $1: 10$. Biotinylated anti-rabbit secondary antibody (Dakopatts, Hamburg, Germany), diluted 1:400 in TBS, was incubated for $30 \mathrm{~min}$ before the application of avidin-biotinperoxidase complex (Dakopatts), diluted 1:200 in TBS, for $30 \mathrm{~min}$. Labeled antigen was visualized with standard diaminobenzidine techniques.

\section{Acknowledgements}

This work was supported by a grant of the Fortüne-Programm of the University of Tübingen to W Roth. We thank P Liston (Ottawa, Canada) for providing XIAP antibody, and $\mathrm{H}$ Walczak and $\mathrm{PH}$ Krammer (Heidelberg, Germany) for providing FLIP antibody.

\section{References}

1. Smith CA, Farrah T and Goodwin RG (1994) The TNF receptor superfamily of cellular and viral proteins: activation, costimulation, and death. Cell 76: 959-962

2. Tartaglia LA and Goeddel DV (1992) Two TNF receptors. Immunol. Today 13: $151-153$

3. Nagata S (1997) Apoptosis by death factor. Cell 88: 355-365

4. Ashkenazi A and Dixit VM (1998) Death receptors: signaling and modulation. Science 281: 1305-1308

5. Anderson DM, Maraskovsky E, Billingsley WL, Dougall WC, Tometsko ME, Roux ER, Teepe MC, DuBose RF, Cosman D and Galibert L (1997) A homologue of the TNF receptor and its ligand enhance T-cell growth and dendritic-cell function. Nature 390: $175-179$

6. Wong BR, Rho J, Arron J, Robinson E, Orlinick J, Chao M, Kalachikov S, Cayani E, Bartlett FS, Frankel WN, Lee SY and Choi Y (1997) TRANCE is a novel ligand of the tumornecrosis factor receptor family that activates C-Jun N-terminal kinase in T cells. J. Biol. Chem. 272: 25190-25194

7. Mauri DN, Ebner R, Montgomery RI, Kochel KD, Cheung TC, Yu GL, Ruben S, Murphy M, Eisenberg RJ, Cohen GH, Spear PG and Ware CF (1998) LIGHT, a new member of the TNF superfamily, and lymphotoxin alpha are ligands for herpesvirus entry mediator. Immunity 8: 21-30

8. Zhai Y, Guo R, Hsu TL, Yu GL, Ni J, Kwon BS, Jiang GW, Lu J, Tan J, Ugustus M, Carter K, Rojas L, Zhu F, Lincoln C, Endress G, Xing L, Wang S, Oh KO, Gentz R, Ruben S, Lippman ME, Hsieh SL and Yang D (1998) LIGHT, a novel ligand for lymphotoxin beta receptor and TR2/HVEM induces apoptosis and suppresses in vivo tumor formation via gene transfer. J. Clin. Invest. 102: 1142-1151

9. Chicheportiche Y, Bourdon PR, Xu H, Hsu YM, Scott H, Hession C, Garcia I and Browning JL (1997) TWEAK, a new secreted ligand in the tumor necrosis factor family that weakly induces apoptosis. J. Biol. Chem. 272: 32401-32410
10. Hahne M, Kataoka T, Schroter M, Hofmann K, Irmler M, Bodmer JL, Schneider $P$, Bornand T, Holler N, French LE, Sordat B, Rimoldi D and Tschopp J (1998) APRIL, a new ligand of the tumor necrosis factor family, stimulates tumor cell growth. J. Exp. Med. 188: 1185-1190

11. Kelly K, Manos E, Jensen G, Nadauld L and Jones DA (2000) APRIL/TRDL-1, a tumor necrosis factor-like ligand, stimulates cell death. Cancer Res. 60: 10211027

12. RiegerJ, Naumann U, Glaser T, Ashkenazi Aand WellerM (1998) APO2 ligand:a novel lethal weapon against malignant glioma? FEBS Lett. 427: 124-128

13. Weller M, RiegerJ, Grimmel C, Van MeirEG, de TriboletN, KrajewskiS, ReedJC, von Deimling A and Dichgans J (1998) Predicting chemoresistance in human malignant glioma cells: the role of molecular genetic analyses. Int. J. Cancer 79: 640-644

14. Roth W, Fontana A, Trepel M, Reed JC, Dichgans J and Weller M (1997) Immunochemotherapy of malignant glioma: synergistic activity of CD95 ligand and chemotherapeutics. Cancer Immunol. Immunother. 44: 55-63

15. Wagenknecht B, Schulz JB, Gulbins E and Weller M (1998) Crm-A, bcl-2 and NDGA inhibit CD95L-induced apoptosis of malignant glioma cells at the level of caspase 8 processing. Cell Death Differ. 5: 894-900

16. Roth W and Weller M (1999) Chemotherapy and immunotherapy of malignant glioma: molecular mechanisms and clinical perspectives. Cell. Mol. Life Sci. 56: $481-506$

17. Reed JC (1997) Double identity for proteins of the Bcl-2 family. Nature 387: 773 776

18. Liston P, Roy N, Tamai K, Lefebvre C, Baird S, Cherton-Horvat G, Farahani R, McLean M, Ikeda JE, MacKenzie A and Korneluk RG (1996) Suppression of apoptosis in mammalian cells by NAIP and a related family of IAP genes. Nature 379: $349-353$

19. Irmler M, Thome M, Hahne M, Schneider P, Hofmann K, Steiner V, Bodmer JL, Schröter M, Burns K, Mattmann C, Rimoldi D, French LE and Tschopp J (1997) Inhibition of death receptor signals by cellular FLIP. Nature 388: 190-195

20. Nagata S (1997) Apoptosis by death factor. Cell 88: 355-365

21. Griffith TS, Wiley SR, Kubin MZ, Sedger LM, Maliszewski CR and Fanger NA (1999) Monocyte-mediated tumoricidal activity via the tumor necrosis factorrelated cytokine, TRAIL. J. Exp. Med. 189: 1343-1354

22. Kayagaki N, Yamaguchi N, Nakayama M, Kawasaki A, Akiba H, Okumura Kand Yagita $H(1999)$ Involvement of TNF-related apoptosis-inducing ligand in human CD4+ T cell-mediated cytotoxicity. J. Immunol. 162: 2639-2647

23. Pitti RM, Marsters SA, Lawrence DA, Roy M, Kischkel FC, Dowd P, Huang A, Donahue CJ, Sherwood SW, Baldwin DT, Godowski PJ, Wood WI, Gurney AL, Hillan KJ, Cohen RL, Goddard AD, Botstein D and Ashkenazi A (1998) Genomic amplification of a decoy receptor for Fas ligand in lung and colon cancer. Nature 396: $699-703$

24. Marsters SA, Yan M, Pitti RM, Haas PE, Dixit VM and Ashkenazi A (2000) Interaction of the TNF homologues BLyS and APRIL with the TNF receptor homologues BCMA and TACl. Curr. Biol. 10: 785-788

25. Wu Y, Bressette D, Carrell JA, Kaufman T, Feng P, Taylor K, Gan Y, Cho YH, Garcia AD, Gollatz E, Dimke D, LaFleur D, Migone TS, Nardelli B, Wei P, Ruben SM, Ullrich SJ, Olsen HS, Kanakaraj P, Moore PA and Baker KP (2000) Tumor necrosis factor receptor superfamily member $T A C l$ is a high affinity receptor for TNF family members APRIL and BLyS. J. Biol. Chem. 275: 35478-35485

26. Weller M, Malipiero U, Aguzzi A, Reed JC and Fontana A (1995) Protooncogene bcl-2 gene transfer abrogates Fas/APO-1 antibody-mediated apoptosis of human malignant glioma cells and confers resistance to chemotherapeutic drugs and therapeutic irradiation. J. Clin. Invest. 95: 2633-2643

27. Kondo S, Barna BP, Morimura T, Takeuchi J, Yuan J, Akbasak A and Barnett GH (1995) Interleukin-1 beta-converting enzyme mediates cisplatin-induced apoptosis in malignant glioma cells. Cancer Res. 55: 6166-6171

28. Wagenknecht B, Glaser T, Naumann U, Kügler S, Isenmann S, Bähr M, Korneluk R, Liston P and Weller M (1999) Expression and biological activity of X-linked inhibitor of apoptosis (XIAP) in human malignant glioma. Cell Death Differ. 6: $370-376$

29. Deveraux QL, Takahashi R, Salvesen GS and Reed JC (1997) X-linked IAP is a direct inhibitor of cell-death proteases. Nature 388: $300-304$ 
30. Deveraux QL, Roy N, Stennicke HR, Van Arsdale T, Zhou Q, Srinivasula SM, Alnemri ES, Salvesen GS and Reed JC (1998) IAPs block apoptotic events induced by caspase-8 and cytochrome $c$ by direct inhibition of distinct caspases. EMBO J. 17: 2215-2223

31. Stehlik C, de Martin R, Kumabashiri I, Schmid JA, Binder BR and Lipp J (1998) Nuclear factor (NF)-kappaB-regulated X-chromosome-linked iap gene expression protects endothelial cells from tumor necrosis factor alpha-induced apoptosis. J. Exp. Med. 188: 211-216

32. Glaser T, WagenknechtB, Groscurth P, KrammerPH and Weller M (1999) Death ligand/receptor-independent caspase activation mediates drug-induced cell death in malignant glioma cells. Oncogene 18: 5044-5053

33. Roth W, Wild-Bode C, Platten M, Grimmel C, Melkonyan HS, Dichgans J and Weller M (2000) Secreted Frizzled related proteins inhibit motility and promote growth of malignant glioma cells. Oncogene 19: 4210-4220
34. Scaffidi C, Schmitz I, Krammer PH and Peter ME (1999) The role of c-FLIP in modulation of CD95-induced apoptosis. J. Biol. Chem. 274: 1541-1548

35. Roth W, Grimmel C, Rieger L, Strik H, Takayama S, Krajewski S, Dichgans J, Reed JC and Weller M (2000) Bag-1 and bcl-2gene transfer in malignant glioma: Modulation of cell cycle regulation and apoptosis. Brain Pathol. 10: 223-234

36. Roth W, Isenmann S, Naumann U, Kügler S, Bähr M, Dichgans J, Ashkenazi A and Weller M (1999) Locoregional Apo2L/TRAIL eradicates intracranial human malignant glioma xenografts in athymic mice in the absence of neurotoxicity. Biochem. Biophys. Res. Commun. 265: 479-483 